\title{
LEVANTAMENTO DE DADOS SOBRE A VACINAÇÃO CONTRA O VÍRUS INFLUENZA E A HIPÓTESE DE VACINAÇÃO CONTRA O CORONAVÍRUS
}

\author{
DATA COLLECTION ABOUT VACCINATION AGAINST INFLUENZA VIRUS \\ AND HYPOTHESIS OF VACCINATION AGAINST CORONAVIRUS
}

Hugo Oikawa ${ }^{1}$, Maria Luísa Colpini Meurer ${ }^{1}$, Mateus Henrique Aderaldo Amichi ${ }^{1}$, Luis Renato Manfredini Hapner ${ }^{2}$.

${ }^{1}$ UNINGÁ - Centro Universitário Ingá, Maringá, PR, Brasil.

${ }^{2}$ Universidade Federal do Paraná, Curitiba, PR, Brasil.

\section{RESUMO}

A cobertura vacinal adequada é de extrema importância para o controle e prevenção de doenças, além disso, as vacinas são cada vez mais completas. Tendo o calendário vacinal, padronizado pela Organização Mundial de Saúde, elaborado para priorizar indivíduos saudáveis. Sendo a vacina contra influenza, administrada anualmente para grupos elegíveis que comparecem aos centros de saúde. Atualmente o Brasil está envolvido no desenvolvimento de duas Vacinas Contra o Coronavírus (VacCo) que após os testes e a aprovação poderá ser comercializada e aplicada. Ao atingir esta etapa, é importante a adesão popular à vacinação para prevenção de moléstias e para diminuir a transmissão do vírus. Analisar a partir dos valores percentuais da População Estimada Residente no Brasil e Regiões (PopEst) com a Cobertura Vacinal (CobVac) e a quantidade de Doses Aplicadas de Vacinas contra o Vírus Influenza (Vaclnf), e os números de Óbitos Acumulados por Coronavírus por 100 milhões de habitantes (ObtCo). Após isso, discutir os resultados obtidos, assim, contribuir e ampliar os estudos sobre este assunto. A fonte das informações de ObtCo registrados até o dia 10 de outubro de 2020, CobVac e Vaclnf, no período de 2010 e 2020, extraídas do Ministério da Saúde, utilizando o TABNET no site DATASUS e openDataSUS. Para PopEst nos anos de 2010 até 2020 fornecidas pelo Instituto Brasileiro de Geografia e Estatística. Com o auxílio de tabelas e gráficos do programa Microsoft Excel para a comparação dos valores. A 1a comparação de dados foi entre PopEst e CobVac, no período de 2010 até 2020. Tendo o melhor CobVac no ano de 2015. Sendo o menor em 2016 e em 2020 com o penúltimo. A $2^{\circ}$ comparação de dados foi entre PopEst e Vaclnf, no período de 2010 até 2020 . Os valores percentuais para esta vacina não atingiram 9\%. Apresentando aumento em 2020 em comparação aos 3 anos anteriores. A $3^{\underline{a}}$ comparação de dados foi entre ObtCo, CobVac e Vaclnf no período de 2020. Apresentando um possível padrão associativo na Região Sul de menor ObtCo, maior CobVac e segunda Vaclnf. Já a Região Norte também apresentou correspondências com maior ObtCo, segunda menor CobVac, e segunda menor Vaclnf. O objetivo deste estudo foi atingido e pelos dados obtidos é evidente 0 baixo Vaclnf. Assim, caso os números de vacinados pela VacCo forem semelhantes aos números de Vaclnf, é bem provável que ocorra baixa vacinação. Portanto, novos estudos com dados obtidos após o término da vacinação são necessários para discutir as hipóteses a seguir, criadas a partir 
deste artigo: Se os números apresentarem-se abaixo do esperado, como incentivar a população a aderir ao uso da VacCo? Quais os motivos de uma taxa baixa Vaclnf? Os órgãos responsáveis pelo incentivo a vacinação poderiam contribuir para melhorar a Vaclnf? Se números satisfatórios de VacCo, como adequar também para as outras? As estratégias do Programa Nacional de Imunizações podem ser aprimoradas para atender a população de maneira mais efetiva?

Palavras-chave: Cobertura vacinal. Coronavírus. Influenza humana. Programas de imunização. Vacinas. 